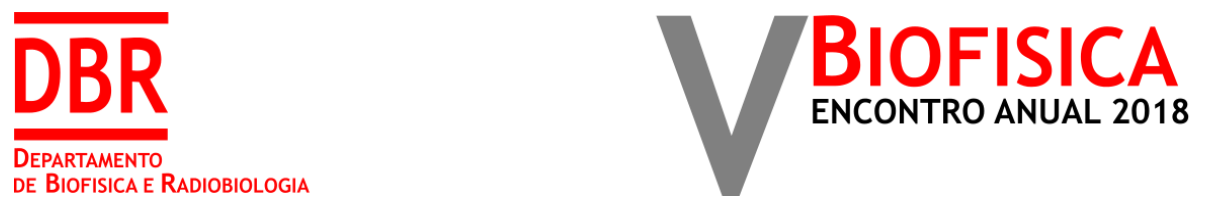

\title{
NANOPORO DA ALFATOXINA NA DETECÇÃO DE PESTICIDA DA CLASSE DOS ORGANOESTÂNICOS
}

\author{
Artur Alves Rodrigues da Silva ${ }^{1 *}$, Janilson José da Silva Júnior ${ }^{1}$, Dijanah Cota Machado ${ }^{1}$, Juliana Pereira de Aguiar ${ }^{1}$, \\ Cláudio Gabriel Rodrigues ${ }^{1}$
}

${ }^{1}$ Laboratório de Biofísica das Membranas e Células-tronco Dr. Oleg Krasilnikov, UFPE; *arturalves1994@ufpe.br

\begin{abstract}
INTRODUÇÃO
Os impactos causados pelas atividades antrópicas têm efeitos sobre os diversos ecossistemas, causando diversas desordens no meio ambiente. Entre essas atividades, a produção e utilização de produtos industriais contendo compostos organoestânicos (OTs) contribuem diretamente nesse processo $(\mathrm{HOCH}, 2001)$. Os compostos OTs se enquadram na categoria dos organometálicos por apresentarem ao menos uma ligação entre metais ou semimetais com grupos orgânicos. A fórmula geral assumida é $R_{(n)} S n X_{(4-n)}$, sendo $\mathrm{R}$ um grupo alquil ou aril e $\mathrm{X}$ uma espécie aniônica (cloreto, hidró xido, óxido, entre outros) (GODOI et al., 2003). A aplicação de produtos à base de OTs abrange na sua grande maioria a produção de biocidas, utilizados na agricultura e atividade marinha (SOUSA et al., 2014). A partir do uso generalizado desses compostos grandes níveis passaram a ser encontrados no ambiente. A preocupação com essas substâncias no meio ambiente vem da capacidade da maioria dos triorganoestânicos, a exemplo do Cyhexatin, de atuarem como disruptores endócrinos, causando transtornos em diversas vias de conversão hormonais mediadas por enzimas (PAGLIARANI et al., 2013). Devido aos efeitos tóxicos evidenciados, o Cyhexatin teve seu uso restringido por agências de regulação. No Brasil a agência nacional de vigilância sanitária (ANVISA), em 2011, proibiu o uso e comercialização. Em face da necessidade de controlar os níveis desses elementos baseado no que foi estabelecido e recomendado pelos órgãos de controle ambiental, surgiu a perspectiva para o desenvolvimento ou adaptaç ão de plataformas que permitam a detecção dos OTs. Metodologias baseadas na utilização da cromatografia gasosa (CG) ou líquida (HPLC), acoplado a um sistema de detecção estão entre as técnicas mais empregadas. Contudo, alguns problemas dificultam a aplicaçã o dessas metodologias no dia-a-dia como: alto custo operacional, falta de limites de detecção próximos do que é exigido pelas agê ncias de regulação para amostras líquidas e exaustivas etapas de derivação (MORABITO et al., 2000; HOCH et al., 2001; GUl et al., 2016). Nesse contexto, biossensores baseados em poros nanomé tricos estão ganhando destaque neste cenário, particularmente devido à capacidade dessas estruturas em detectar, identificar e caracterizar moléculas. 0 nanoporo formado pela alfatoxina de Staphylococcus aureus (aHL) (Fig. 1), inserido em uma bicamada lipídica plana é caracterizado pela oligomerização de sete subunidades e dividida em três regiões bem definidas (Troncular, anelar e copal) (AGUIAR et al., 2015). Esta estrutura tornou-se uma plataforma de biossensoriamento estocástico com grande importâ ncia permitindo a investigação das propriedades de moléculas unitá rias em solução aquosa sem destrui-la e com a capacidade de fornecer limites de detecção baixíssimos. Dentre trabalhos já
\end{abstract}

desenvolvidos utilizando a alfatoxina como ferramenta para detecç ão de contaminantes ambientais, recentemente foi relatado o emprego dessa metodologia para caracterização e detecção de microcistinas (RODRIGUES et al., 2012). No presente trabalho utilizamos a metodologia de detecção estocástica baseado no nanoporo da alfatoxina, com a finalidade de realizar a identificaçã o do Cyhexatin em meio aquoso e fornecer uma nova abordagem de detecção para compostos dessa mesma classe. A motivação para a escolha do Cyhexatin é que este é um dos principais compostos organoestânicos utilizados na agricultura, amplamente empregado nas diversas culturas e também devido ao número reduzido de estudos que fornecem técnicas alternativas para monitorar seu ní vel no meio ambiente (GODOI et al., 2003).

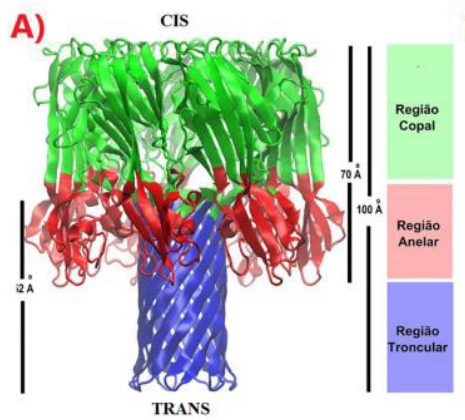

B)

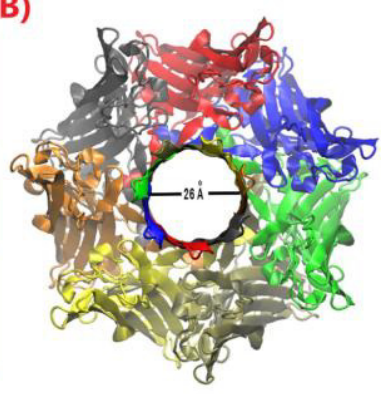

Figura 1. Nanoporo da alfatoxina. A) Visão lateral do nanoporo com as regiões (copal, anelar e troncular) definidas em três cores distintas. Indicação dos lados CIS e TRANS e das dimensões do nanoporo através das colunas empilhadas e das barras laterais. B) Vista superior das subunidades que compõe o nanoporo da alfatoxina discriminadas cada uma por uma cor, adicionalmente a barra horizontal representa o diâmetro do lado CIS do nanoporo (Fonte: AGUIAR et al., 2015).

\section{MATERIAIS E MÉTODOS}

Todas as bicamadas lipídicas planas livres de solvente foram confeccionadas com o lipídeo diftanoil glicerofosfocolina (DPhPC) (Avanti Lipids, USA) conforme a técnica de Montal \& Mueller, (1972). Esta técnica fundamenta-se na justaposição de dois filmes monomoleculares de lipídeos, num orifício com aproximadamente $50 \mu \mathrm{m}$ de diâmetro, de uma partição de $\operatorname{Teflon}^{\circledR}$ (Fig. 2). Esta partição é responsável por separar a câmara experimental, també $\mathrm{m}$ de Teflon $^{\oplus}$, em dois compartimentos (CIS e TRANS). Para a formação da bicamada lipídica, inicialmente adicionamos solução eletrolítica em cada compartimento ficando o nível da solução abaixo do orifício. Em seguida foi adicionado à superfície da soluçã o aquosa $15 \mu \mathrm{l}$ de uma solução contendo DPhPC $2 \%(\mathrm{p} / \mathrm{v})$ em hexano, que após a evaporação do próprio hexano, ocorre a formaç ão de um filme lipídico na superfície da solução aquosa em cada 
um dos compartimentos. A adição de mais solução aquosa no compartimento TRANS permite a elevação do nível acima do orifí cio, formando a primeira monocamada. Por fim, para formação da bicamada repetimos esse mesmo procedimento no lado CIS. Após a formação da bicamada lipídica, foi adicionado $0,5 \mu \mathrm{l}$ de alfatoxina $(0,07 \mathrm{mg} / \mathrm{l})$ (Calbiochem, USA) à solução banhante do lado CIS da câmara experimental, atingindo uma concentração final de $\sim 2$ $\mathrm{ng} / \mathrm{L}$, que é suficiente para formação de um único nanoporo da alfatoxina. A solução banhante foi composta por $\mathrm{KCl} 4 \mathrm{M}$, TRIS 5

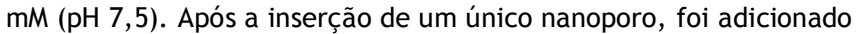
ao compartimento TRANS o Cyhexatin em concentrações crescentes a partir de $0,005 \mathrm{nM}$. Os experimentos foram realizados em condiçõ es de fixação de voltagem, através da utilização de um gerador de funções (Hewlett Packard, modelo 3310B), um filtro butterworth a $15 \mathrm{KHz}$ (Frequency devices, modelo 902), um amplificador de patch clamp (Axonpatch 200B), uma placa conversora analógico-digital (National instruments modelo BNC-2090), acoplado a um microcomputador. 0 protocolo experimental consistiu na aplicação de potenciais de -200 a $200 \mathrm{mV}$ (incrementos de $20 \mathrm{mV}$ ) e registro da corrente iônica. Toda a etapa de análise e obtenção dos parâ metros biofísicos foi realizada como relatado por krasilnikov et al. (2006).
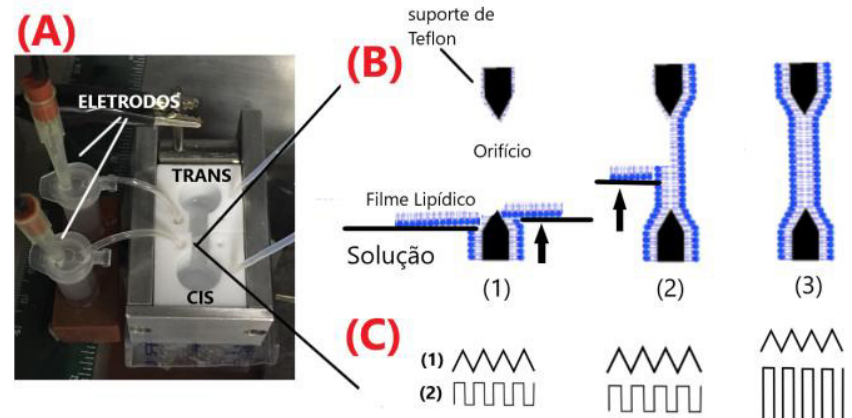

(3) (2) ПТП

MM

Figura 2. llustração da câmara experimental e esquema representativo de formação da bicamada lipídica. A) câmara de Teflon ${ }^{\circledast}$ com indicação dos compartimentos CIS/TRANS e eletrodos de conexão com a interface eletrônica. B) Etapas de formação da bicamada: (1) elevação do primeiro filme lipídico, (2) com a formação da primeira monocamada, elevaç ão do segundo filme lipídico e (3) formação final da bicamada. C) As etapas de formação das bicamadas lipídicas foram monitoradas pelo aumento da corrente capacitiva: (1) perfil do potencial aplicado ao sistema (2) aumento da corrente capacitiva em resposta aos eventos ocorridos em decorrência do processo de formação da membrana.

\section{RESULTADOS E DISCUSSÃO}

Inicialmente foram obtidos parâmetros importantes que fornecem informações quanto à interação do composto organoestânico selecionado, neste caso o Cyhexatin, com o nanoporo da alfatoxina. 0 primeiro deles foi a análise da influência do potencial transmembrana sobre a condutância do nanoporo, tanto na ausê ncia do Cyhexatin quanto em sua presença. Esse parâmetro permite identificar em qual potencial a influência do analito sobre a condutância do nanoporo é máxima (MELO et al., 2015). Para isto, adicionamos $1 \mu \mathrm{M}$ do Cyhexatin ao lado TRANS e aplicamos um protocolo de voltagem $(80 \mathrm{a} 160 \mathrm{mV})$, os resultados são mostrados na Figura 3. Na concentração utilizada houve uma diminuição de aproximadamente $10 \%$ da condutância. Estes valores de potencial favorecem as condições mais adequadas de interação Cyhexatinnanoporo. Estudos de Samuel et al.,1998 e Ramalho et al.,2010 indicam a possibilidade dos compostos organoestânicos adquirirem carga residual positiva em solução aquosa. Isso pode explica a diminuição significativa da condutância do nanoporo em altas voltagens positivas, pois carregadas eletricamente as moléculas são "empurradas" através do lúmen no nanoporo para o lado CIS. Esses achados refletem que as voltagens ideais para detecção do Cyhexatin são 140 e $160 \mathrm{mV}$.

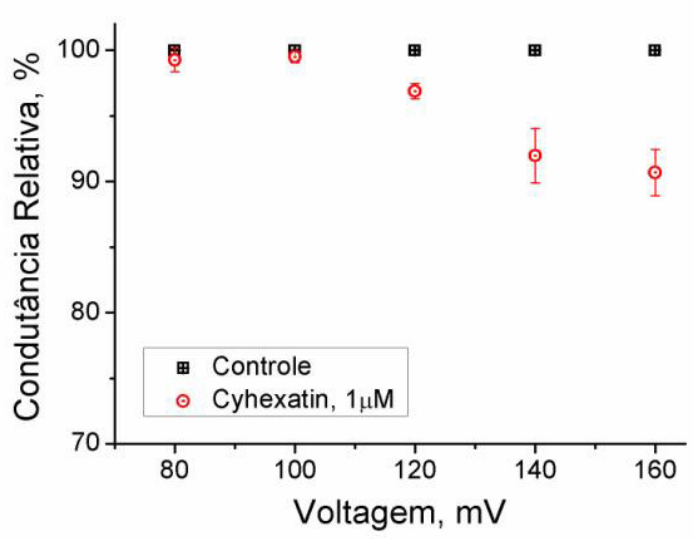

Figura 3. Efeito do Cyhexatin sobre a condutância do nanoporo da alfatoxina. A condutâ ncia do nanoporo na ausência do composto foi considerada 100\% (Controle). Na presença de $1 \mu \mathrm{M}$ do Cyhexatin, uma diminuição da condutância com maior proeminência é observada nos potenciais de 140 e $160 \mathrm{mV}$. (口) Controle e ( $\circ$ ) Cyhexatin.

Em seguida avaliamos a capacidade do nanoporo da alfatoxina, quando incorporado a uma bicamada lipídica plana, em detectar o Cyhexatin, como podemos observar na Figura 4. 0 princípio de detecção do nanoporo é baseado na interação do Cyhexatin com o lúmen do nanoporo, induzindo uma redução da corrente iônica, denominado de evento de bloqueio. Por ser uma molécula orgânica pequena, estudos semelhantes utilizando a alfatoxina já demonstraram a capacidade dessa plataforma na detecção de molé culas do mesmo tamanho, como os agentes organofosforados (WANG et al., 2009), reforçando que o mesmo pode ser adaptado para os compostos organoestânicos.

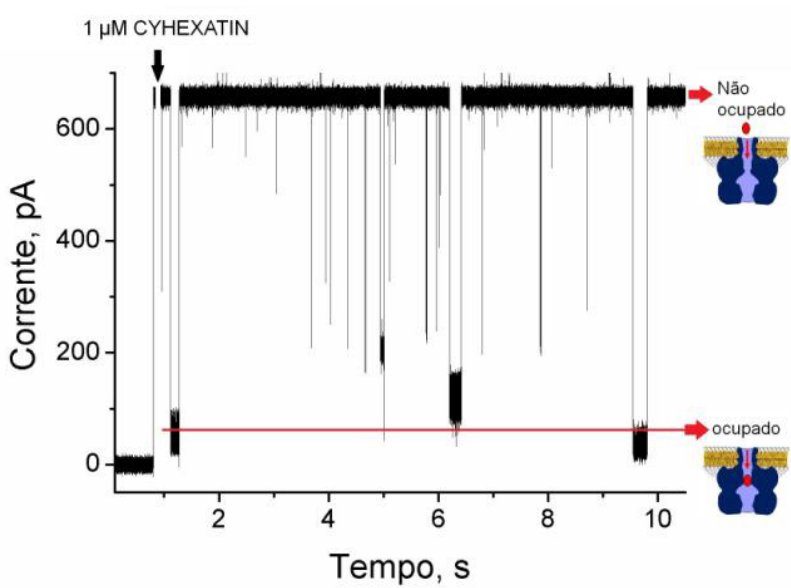

Figura 4. Perfil dos bloqueios da corrente iônica induzidos pela translocação do Cyhexatin através do nanoporo da alfatoxina. Foi adicionado $1 \mu \mathrm{M}$ do Cyhexatin no lado TRANS e aplicado um potencial transmembrana de $160 \mathrm{mV}$ em solução de $\mathrm{KCl} 4 \mathrm{M}, \mathrm{pH} 7,5$.

Posteriormente, demos sequência na obtenção do limite de detecç ão fornecido pela técnica, permitindo uma avaliação preliminar da capacidade do nanoporo da alfatoxina como um elemento sensor para o Cyhexatin e compostos de mesma classe. Os resultados obtidos podem ser observados na Figura 5 , onde foi calculada a frequência de eventos em função da concentração do Cyhexatin. A menor concentração detectada foi no valor de 0,005 nM. Outros estudos, utilizando técnicas como a espectrometria de massas acoplado a cromatografia gasosa (CG-MS), determinaram concentrações de Cyhexatin apenas em resíduos de frutas (MA et al., 2015), não havendo na literatura nada que se refira a determinação do composto em matrizes líquidas. Portanto, além dos valores detectados estarem abaixo do que os órgãos de regulamentação preconizam, o nanoporo da alfatoxina pode 
oferecer uma nova via de monitorização ambiental, possibilitando o controle do nível do Cyhexatin em rios ou aquíferos.

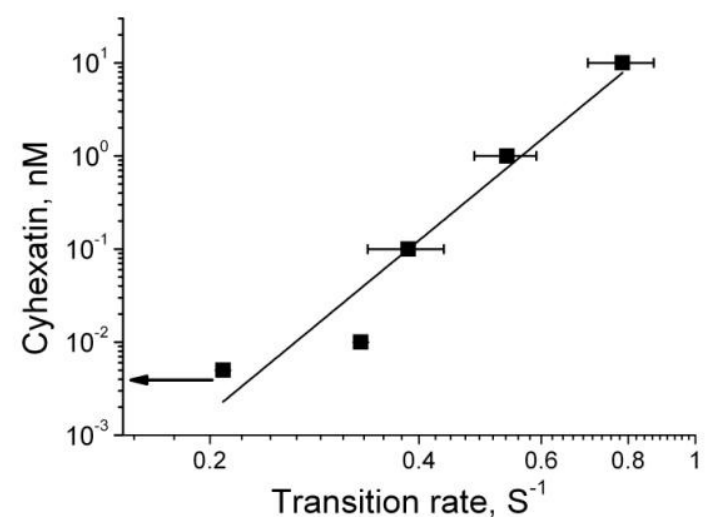

Figura 5. Limite de detecção do Cyhexatin. A menor concentração detectada foi de 0,005 $\mathrm{nM}$, como indicado na seta. A solução banhante foi composta de $\mathrm{KCl} 4 \mathrm{M}$, TRIS $5 \mathrm{mM}(\mathrm{pH}$ $7,5)$. O Cyhexatin foi adicionado no lado TRANS e aplicado potencial transmembrana de $140 \mathrm{mV}$. Os dados são representativos da média e desvio padrão de três experimentos.

\section{CONCLUSÕES}

O nanoporo da alfatoxina funciona como biossensor estocástico para detecção de compostos organoestânicos em meio aquoso.

\section{REFERÊNCIAS}

AGUIAR, J. P.; JÚNIOR, J. J. S.; MACHADO, D. C.; MELO, M. C. A.; RODRIGUES, C. G. Biossensoriamento estocástico via nanoporo proteico individual no desenvolvimento de ferramentas analíticas. Quim. Nova, v. 38, n. 6, p. 817-827, 2015.

GODOI, A. F. L.; FAVORETO, R.; SANTIAGO-SILVA, M. Contaminação ambiental por compostos organoestânicos. Quim. Nova, v. 26, n. 5, p. 708-716, 2003.

GUI, W.; TIAN, C.; SUN, Q.; LI, S.; ZHANG, W.; TANG, J.; ZHU, G. Simultaneous determination of organotins pesticides by HPLC-ICPMS and their sorption, desorption, and transformation in freshwater sediments. Water research, v. 95, p. 185-194, 2016. $\mathrm{HOCH}$, M. Organotin compounds in the environment. Applied Geochemistry, v. 16, p. 719-743, 2001.

KRASILNIKOV, O. V.; RODRIGUES, C. G.; BEZRUKOV, S. M. Single polymer molecules in a protein nanopore in the limit of Strong polymer-pore attraction. PRL, v. 97, n. 1, 2006.

MA, Y. N.; GUI, W. J.; ZHU, G. N. The analysis of azocyclotin and Cyhexatin residues in fruits using ultrahigh-performance liquid chromatography-tandem mass spectrometry. Anal. Methods, v. 7, 2015.

MELO, M. C. A.; TEXEIRA, L. R.; POL-FACHIN, L.; RODRIGUES, C. G. Inhibition of the hemolytic activity caused by Staphylococcus aureus alpha-hemolysin through isatin-schiff copper(II) complexes. FEMS Microbiology Letters, v. 363, n. 1, 2016.

MONTAL, M.; MUELLER, P. Formation of biomolecular membranes from lipid monolayers and study of their electrical properties. PNAS, v. 69, n. 12, p. 3561-3566, 1972.

MORABITO, R.; MASSANISSO, P.; QUEVAUVILLER, P. Derivatization methods for the determination of organotin compounds in environmental samples. Trends in analytical chemistry, v. 19, 2000.

PAGLIARANI, A.; NESCl, S.; VENTRELLA, V. Toxicity of organotins compounds: Shared and unshared biochemical targets and mechanisms in animal cells. Toxicology in vitro, v. 27, p. 978-990, 2013.
RODRIGUES, C. G.; CHEVTCHENKO, S. F.; KRASILNIKOV, O. L.; MACHADO, D. C.; AGUIAR, J. A.; SILVA, J. J. Utilização de um nanoporo proteico para detecção, identificação, quantificação e monitoramento em tempo real de microcistinas em sistemas aquosos.BR pat 000322, 2012.

RAMALHO, T. C.; ROCHA, M. V. J.; DA CUNHA, E. F. F.; OLIVEIRA, L. C. A.; CARVALHO, K. T. G. Understanding the Molecular Behavior of Organotin Compounds to Design their Effective Use as Agrochemicals: Exploration via Quantum Chemistry and Experiments. J. Biomolecular Structure \& Dynamics, v. 28, n. 2, p. 227-238, 2010.

SAMUEL, P. M.; ROY, S.; JAISWAL, K. A.; RAO, J. V. Differential effects of organometallic tin compounds on $\mathrm{Na}^{+} / \mathrm{K}^{+}$-ATPase activity. J. Appl. Toxicol, v. 18, p. 383-386, 1996.

SOUSA, A. C. A.; PASTORINHO, M. R.; TAKAHASHI, S.; TANABE, S. History on organotins compounds, from snails to humans. Environ. Chem Lett, v. 12, p. 117-137, 2014.

WANG, D.; ZHAO, Q.; ZOYSA, R. S. S.; GUAN, X. Detection of nerve agente hydrolytes in an engineered nanopore. Sensors and actuators B: chemical, v. 139, p. 440-446, 2009.

*Apoio financeiro: CAPES, CNPq, UFPE. 